\title{
DOSSIE
}

Sociologias, Porto Alegre, ano 15, no 32, jan./abr. 2013, p. 14-17

\section{Desigualdade Política, Democracia e Governança Global}

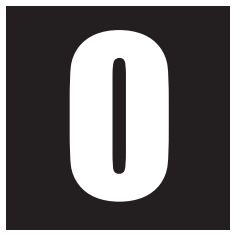

dossiê "Desigualdade Política, Democracia e Governança Global" examina como a democracia e a governança global estão relacionadas às desigualdades políticas. A governança global é aqui tratada como um sistema que regula como as decisões que afetam as nações, e as inter-relações entre as nações, são tomadas e implementadas. Enquanto objetos de análise, 'democracia' e 'governança global' têm sido abordados com frequência nos campos das relações internacionais e da ciência política. Porém, apenas recentemente as conexões entre os dois chamaram a atenção dos sociólogos. Já as desigualdades sociais, políticas e a sua estruturação nas sociedades estão no centro da agenda de pesquisas da sociologia, desde a sua constituição como disciplina. O foco no dossiê recai sobre as 'desigualdades políticas', entendidas como padrões de influência sobre as estruturas de governança estruturalmente diferenciadas e consideradas como elementos chave para a compreensão de como a governança global funciona na teoria e na prática.

O dossiê conecta as duas discussões - a que trata da 'democracia' e 'governança global' e a que aborda 'desigualdades políticas' - no esforço de avançar o debate sobre as temáticas tanto isoladamente como no que se refere às suas conexões. Em primeiro lugar, dá continuidade ao diálo- 
go iniciado no Congresso Mundial da International Sociological Association (ISA), em Gotemburgo, Suécia, em 2010, quando Christopher Chase-Dunn e Alberto Martinelli organizaram a sessão 'Democratizando a Governança Global' (Democratizing Global Governance). Na ocasião, os organizadores descreveram a sessão como um momento de análise 'das questões conceituais e empíricas no estudo da governança global e do esforço histórico e contemporâneo de democratização do sistema global'. Em segundo lugar, é caudatário do debate apresentado no volume especial (volume 41), de 2011, do International Journal of Sociology (IJS), 'Desigualdade Política na América Latina' (Political Inequality in Latin América), em 2011, editado pelos Professores Soraya Vargas Cortes e Joshua Kjerlf Dubrow, o qual, por sua vez, amplia a discussão iniciada no IJS, volume 37, no 04, de 2008, sobre as 'Causas e Conseqüências da Desigualdade Política em uma Perspectiva Comparada' (Causes and Consequences of Political Inequality in CrossNational Perspective), editado pelo Professor Dubrow.

O presente dossiê é composto por cinco artigos. Os três primeiros artigos apresentam um caráter ensaístico. Embora as análises se refiram a inúmeras pesquisas empíricas que abordam as temáticas focalizadas, procuram, de diferentes maneiras, responder, na forma de ensaios metainterpretativos sobre as análises de outros autores, a indagações relativas às interconexões entre 'democracia', 'globalização' e 'desigualdades políticas'. Os dois últimos apresentam resultados de pesquisa empíricas,

O primeiro estudo, 'Democracia: transformações passadas, desafios presentes e perspectivas futuras', elaborado pelo Professor John Markoff, da Universidade de Pittsburgh, nos Estados Unidos da América, aborda o campo conceitual de discussões sobre a democracia em uma perspectiva histórica. $\mathrm{O}$ argumento é que a democracia, inclusive a moderna, vem mudando continuamente, mas a noção de territorialidade delimitada se mantinha como pressuposto central. No início do século vinte um, no entanto, existem várias razões para que se antecipe a ocorrência de mudanças conceituais importantes. Tais mudanças provocam questionamentos sobre se a falta de 
solidariedade e identidades que atravessem fronteiras nacionais permitiria a existência de democracia transnacional; se estruturas administrativas de vasto escopo territorial podem se tornar genuinamente accountable à cidadania; se Estados ricos e poderosos vão obedecer a estruturas superiores que limitem sua autonomia. O segundo ensaio, 'Democratização da Governança Global: perspectivas históricas mundiais', de autoria dos Professores Christopher Chase-Dunn e Bruce Lerro, da Universidade de California-Riverside, nos Estados Unidos da América, examina a controversa ideia de democracia global. Ele apresenta uma visão histórica mundial sobre a evolução da ideia de governança global e examina os movimentos sociais contemporâneos que procuram democratizar as instituições de governança global. O terceiro artigo 'Governança Global Democrática, Desigualdade Política e a Hipótese da Resistência Nacionalista', escrito pelo Professor Joshua Kjerulf Dubrow, da Academia Polonesa de Ciências, trata do modo como a governança global de fato funciona, destacando que as desigualdades políticas estão no centro do processo de governança global. Argumenta ainda que, quando os estudiosos argumentam que a governança global é inevitável, dado o crescimento dos problemas de escopo global, desconsideram a possibilidade de que aconteça o oposto disso: apesar dos crescentes problemas globais, as nações vão evitar compromissos internacionais que limitem sua habilidade de agir de acordo com seu auto-interesse paroquial. Ou seja, quanto mais problemas de escopo global, maior será o ressurgimento nacionalista.

Os dois artigos finais abordam dimensões diversas dos três termos que compõem o foco temático do dossiê. O estudo "Participação Social e Desigualdades nos Conselhos Nacionais", elaborado pelos pesquisadores Joana Alencar, Isadora Cruxên, Igor Fonseca, Roberto Pires e Uriella Ribeiro do Instituto de Pesquisas Econômicas Aplicadas (IPEA), examina as relações entre 'democracia' e 'desigualdades políticas' nos Conselhos de Políticas Públicas brasileiros. Os conselhos, apesar de estarem diretamente ligados a órgãos do poder executivo, são instituições híbridas que agregam Estado e sociedade, constituindo-se em canais de participação 
política, deliberação institucionalizada e divulgação das ações do governo. $\mathrm{O}$ artigo investiga se, e de que maneiras, as relações de desigualdades sociais e políticas tradicionalmente manifestas entre pessoas de diferentes regiões, classe, cor/raça e sexo se manifestam nos conselhos nacionais. O objetivo central é observar em que medida esses espaços favorecem a redução de desigualdades ou, mesmo, em quais aspectos algumas desigualdades são reproduzidas. O artigo 'Movimentos Sociais, Ativismo Constitucional e Narrativa Democrática na Argentina Contemporânea', da Professora Gabriela Delamata, da Universidade Nacional de General San Martín, Argentina, analisa as relações entre sociedade, movimentos sociais e o marco constitucional na Argentina. Focaliza as transformações nos padrões de entendimento sobre direitos humanos nos marcos constitucionais e do direito internacional. O estudo argumenta que a Constituição reformada em 1994 funciona como um espaço de disputa acerca do sentido da democratização e da relação entre sociedade e Constituição, tendo em vista também os marcos legais internacionais e a sua crescente influência nos espaços político-institucionais nacionais.

Nossa expectativa é a de que o dossiê insira no debate da sociologia, no Brasil, a questão das relações existentes entre 'globalização', 'democracia' e 'desigualdade política', de modo a que no futuro os sociólogos do país participem do esforço internacional de construção coletiva de uma teoria de sobre a temática.

Soraya Vargas Cortes é professora associada da Universidade Federal do Rio Grande do Sul (UFRGS), pesquisadora do CNPq e coordenadora do Grupo de Pesquisas do CNPq 'Sociedade, Participação Social e Políticas Públicas'.

Joshua Kjerulf Dubrow é professor assistente na Academia Polonesa de Ciências, é membro do Board do Research Committee on Social Transformations and Sociology of Development (ISA RC 09) e coordenador do Grupo de Trabalho em Political Inequality, que integra o Research Committee on Political Sociology (ISA RC 18 and IPSA RC 06). 